\title{
Plasminogen Activator
}

National Cancer Institute

\section{Source}

National Cancer Institute. Plasminogen Activator. NCI Thesaurus. Code C16996.

A family of serine proteases that catalyze the proteolytic conversion of plasminogen to plasmin. 